\title{
Interaction effect of job insecurity and role ambiguity on psychological distress in Japanese employees: a cross-sectional study
}

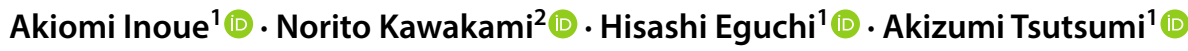

Received: 26 June 2017 / Accepted: 3 January 2018 / Published online: 11 January 2018

(c) The Author(s) 2018. This article is an open access publication

\begin{abstract}
Purpose We examined the interaction effect of job insecurity (JI) and role ambiguity (RA) on psychological distress in Japanese employees.

Methods Overall, 2184 male and 805 female employees from two factories of a manufacturing company in Japan completed a self-administered questionnaire comprising the scales measuring JI (Job Content Questionnaire), RA (National Institute for Occupational Safety and Health Generic Job Stress Questionnaire), psychological distress (K6 scale), and potential confounders (i.e., age, education, family size, occupational class, and work shift). Taking psychological distress as a dependent variable, hierarchical multiple regression analyses were conducted by gender and employment status (i.e., permanent and non-permanent employees). An interaction term of JI $\times$ RA was included in the model.

Results After adjusting for potential confounders, the main effects of JI and RA on psychological distress were significant regardless of gender or employment status. Furthermore, the significant interaction effect of JI $\times$ RA on psychological distress was observed among permanent male employees $(\beta=0.053, p=0.010)$. Post hoc simple slope analyses showed that the simple slope of JI was greater at higher levels of RA (i.e., one standard deviation [SD] above the mean) $(\beta=0.300, p<0.001)$ compared to lower levels of RA (i.e., one SD below the mean) $(\beta=0.212, p<0.001)$. On the other hand, the interaction effect of JI $\times$ RA was not significant among permanent or non-permanent female employees.

Conclusions The present study suggests that higher levels of RA strengthen the association of JI with psychological distress, at least among Japanese permanent male employees.
\end{abstract}

Keywords Japan $\cdot$ Job insecurity $\cdot$ K6 scale $\cdot$ Role stress $\cdot$ Uncertainty

\section{Introduction}

In Japan, due to a prolonged economic recession since the early 1990s, the perception of job security has declined among many employees (Tsutsumi 2016). 'Job insecurity (JI)' is a subjective perception of a potential threat to the continuity of the current job. Greenhalgh and Rosenblatt (1984), who performed the first study on JI, defined it as "the

Akiomi Inoue

akiomi@med.kitasato-u.ac.jp

1 Department of Public Health, Kitasato University School of Medicine, 1-15-1 Kitasato, Minami-ku, Sagamihara 252-0374, Japan

2 Department of Mental Health, Graduate School of Medicine, The University of Tokyo, 7-3-1 Hongo, Bunkyo-ku, Tokyo 113-0033, Japan perceived powerlessness to maintain the desired continuity in a threatened job situation". Since then, many other definitions have been put forward. Among others, Hellgren et al. (1999) have divided JI into two main dimensions, quantitative JI and qualitative JI. Quantitative JI is defined as "the perceived threat of job loss and the worries related to that threat" (De Witte 2005). Qualitative JI is defined as "the perceived threat of impaired quality in the employment relationship, such as deterioration of working conditions, lack of career opportunities, and decreasing salary development" (Hellgren et al. 1999). Because most studies on the association of JI with employees' well-being have focused on the quantitative JI (De Witte et al. 2010), the present study will also concentrate on this dimension. It should be noted that permanent (or regular) employees, who are not likely to be easily laid off, are also not exempt from JI because a company may choose to lay them off if it can no longer afford 
to protect them due to intense competitive pressure (Kuroki 2012).

Some theoretical perspectives can explain the negative psychological consequences of JI. For example, Jahoda's (1982) 'latent deprivation model' has suggested that the possibility of losing one's job threatens the satisfaction of needs, such as income and social contacts, and leads to frustration. Furthermore, Warr's (1984) 'vitamin model' has suggested that JI has a negative effect on employees' well-being due to the associated feelings of unpredictability and uncontrollability. This theoretical relationship between JI and psychological well-being has been epidemiologically demonstrated in the occupational health research field in which several meta-analytic studies have reported the association of JI with poor mental health, such as common mental disorders and depressive symptoms (Cheng and Chan 2008; Stansfeld and Candy 2006; Sverke et al. 2002; Theorell et al. 2015). A more recent systematic review has also reported that JI is strongly associated with depressive symptoms (Kim and von dem Knesebeck 2016).

On the other hand, role ambiguity (RA) has also attracted attention as one of the classical psychosocial determinants of employee health (Hurrell and McLaney 1988). RA has been defined as "the extent to which clarity regarding job performance expectations, methods for carrying out the job, and consequences of performance is lacking" (Rizzo et al. 1970). Based on this definition, RA (or lack of role clarity $[\mathrm{RC}]$ ) is considered, at least theoretically, one of the major stressors at work, because it imposes high cognitive overload on employees who must continuously expend energy to seek appropriate ways to accomplish their job (Fisher and Gitelson 1983; Jackson and Schuler 1985). This, in turn, reduces their psychological well-being as well as the ability to perform effectively. In fact, previous meta-analytic studies have reported the association of RA with depression (Schmidt et al. 2014) as well as with lower job satisfaction (Abramis 1994; Shen 2005), job performance (Abramis 1994), and organizational citizenship behavior (Eatough et al. 2011). A more recent systematic review has also reported that RA is associated with a greater risk of developing common mental health problems (Harvey et al. 2017).

As described above, separate studies have examined the association of JI and RA with poor mental health. On the other hand, Fried et al. (2003) pointed out that JI and RA tap the underlying construct of 'uncertainty' at two different levels in which JI focuses on organization-related uncertainty, whereas RA focuses on job-related uncertainty. Therefore, if employees are in uncertain situation in terms of both their own organization and job, they may be more psychologically distressed. More specifically, the association of JI with psychological distress may be greater when employees perceive higher levels of RA, while it may be weaker when they perceive lower levels of RA (or higher levels of RC). In fact,
Hobfoll's (1989) 'Conservation of Resources (COR)' theory suggests that RC has been identified as a supportive working condition that facilitates comprehension of employees' work responsibilities (Panaccio and Vandenberghe 2011); therefore, it is possible that clear expectations and instructions reduce uncertainty in the workplace and consequently incite feelings of control over an insecure situation. To the best of our knowledge, however, the interaction effect of JI $\times$ RA on mental health has not been fully examined.

The purpose of the present study was to examine the interaction effect of JI $\times$ RA on psychological distress in Japanese employees. It was hypothesized that the association of JI with psychological distress would be greater among those who perceived higher levels of RA than among those who perceived lower levels of RA. Especially in the Japanese society, a traditional gender-role ideology that men are expected to be the primary breadwinners still persists (Katsurada and Sugihara 2002), which is specifically linked to gender differences in experiences and perceptions of JI, with men feeling greater insecurity compared to women (Charles and James 2005). Furthermore, the insecure situation is quite different between permanent and non-permanent employees (Virtanen et al. 2002). Therefore, we conducted statistical analyses by gender and employment status.

\section{Methods}

\section{Study design}

In the present study, we used a part of cross-sectional data collected from the baseline survey of an occupational cohort study on social class and health in Japan (Japanese Study of Health, Occupation, and Psychosocial Factors Related Equity: J-HOPE). More detailed information on the J-HOPE baseline survey is provided elsewhere (Inoue et al. 2014). The analyses were conducted using the J-HOPE first wave dataset as of December 22, 2016. Research Ethics Committee of the Graduate School of Medicine and Faculty of Medicine, The University of Tokyo (No. 2772-(4)), Kitasato University Medical Ethics Organization (No. B12-103), and Ethics Committee of Medical Research, University of Occupational and Environmental Health, Japan (No. 10-004) reviewed and approved the aims and procedures of the present study.

\section{Participant recruitment}

All the employees from two factories of a manufacturing company in Japan $(n=3630)$ were recruited by means of an invitation letter sent by the authors in February 2011. All the variables used in the present study, except employment status, which was obtained from the personnel records of the 
surveyed company, were measured using a self-administered questionnaire. The survey was conducted from March to June 2011.

\section{Measures}

\section{Exposures: job insecurity (JI) and role ambiguity (RA)}

JI was measured using a subscale of the Japanese version of the Job Content Questionnaire (JCQ) recommended version (Haratani 1997; Karasek 1985). The JCQ includes a four-item general JI scale (see Appendix). In this sample, Cronbach's alpha coefficient was 0.50 , indicating low reliability. In fact, the JCQ Center, which authorizes the use of the JCQ, has acknowledged the low reliability of the JI scale and explained this phenomenon with the fact that it collects two types of information on (i) JI and future career prospects and (ii) layoff and work instability history (see http://www.jcqcenter.org/FAQs.html). Although we tried to drop some items to achieve more statistically homogenous scale, we could not obtain a scale with better reliability (i.e., Cronbach's alpha coefficient $>0.70$ ). Furthermore, the JCQ Center has suggested that this approach would decrease the robustness of the scale's interpretability. Therefore, we calculated the total score using the original four items rather than dropping some items. According to the JCQ user's guide (Karasek 1985), the total score ranges from 4 to 17, with a higher score indicating a more insecure situation.

RA was measured using the Japanese version of the National Institute for Occupational Safety and Health Generic Job Stress Questionnaire (NIOSH-GJSQ) (Haratani et al. 1996; Hurrell and McLaney 1988). The NIOSHGJSQ includes a six-item RA scale. Example items are, "I feel certain about how much authority I have" and "There are clear, planned goals and objectives for my job". Items were assessed on a seven-point scale ranging from $1=$ Very inaccurate to $7=$ Very accurate (Rizzo et al. 1970). The total score, ranging from 6 to 42 , was calculated by summing the reversed scores for each item, with a higher score indicating a more ambiguous situation. The English version of the NIOSH-GJSQ was translated into Japanese language, and the internal consistency reliability and validity have been reported to be acceptable for this version (Haratani et al. 1996). In this sample, Cronbach's alpha coefficient was 0.86 .

\section{Outcome: psychological distress}

Psychological distress was measured using the Japanese version of the K6 scale (Furukawa et al. 2008; Kessler et al. 2002). The K6 scale comprises six items measuring the levels of psychological distress, that is, feeling (1) nervous, (2) hopeless, (3) restless or fidgety, (4) so depressed that nothing could cheer you up, (5) everything was an effort, and (6) worthless, on a five-point scale ranging from $0=$ None of the time to $4=$ All of the time. The total score, ranging from 0 to 24 , was calculated by summing the score for each item, with a higher score indicating greater psychological distress. The K6 scale was translated into Japanese language, and the internal consistency reliability and validity have been reported as acceptable for this version (Furukawa et al. 2008). In this sample, Cronbach's alpha coefficient was 0.88 .

\section{Potential confounders}

Demographic and occupational characteristics were considered potential confounders. A previous study showed that the association of psychosocial working conditions with mental health differs as a function of age (de Lange et al. 2006). Additionally, education has been reported to be associated with psychosocial working conditions (Lunau et al. 2015) as well as with mental health (Lorant et al. 2003). Furthermore, Adams et al. (1996) have suggested that the relationship between work and family can have an important effect on the employees' well-being. Therefore, in addition to gender introduced earlier, age, education, and family size were included as confounding demographic characteristics. For occupational characteristics, previous studies have reported a gradient of psychosocial working conditions and health status across occupational classes (Kawakami et al. 2004; Marmot et al. 1991). Furthermore, shift workers have been reported to have poorer mental health (Vogel et al. 2012) as well as to be more exposed to unfavorable working conditions, including higher levels of JI, compared to day workers (Bøggild et al. 2001). Therefore, in addition to employment status introduced earlier, occupational class and work shift were included as confounding occupational characteristics.

Demographic characteristics were measured using the self-administered questionnaire. Age was used as a continuous variable. For education, the original classification in the self-administered questionnaire was five groups based on the previous study conducted in Japan (Kimura et al. 2016): graduate school, college, junior college, high school, and junior high school. However, the proportion of junior high school graduates was quite small; therefore, high school graduates and junior high school graduates were combined into one group. Family size was originally measured as a continuous variable. However, it may not necessarily have a linear association with psychological distress because each family size has different meanings (e.g., marital status, the necessity of child and/or family care, etc). Therefore, family size was treated as a categorical variable. In doing so, those who had a family of five or more were combined into one group.

For occupational characteristics, occupational class and work shift were measured using the self-administered questionnaire, whereas information on employment status 
was obtained from the personnel records of the surveyed company. Employment status was dichotomized into permanent and non-permanent employee. Occupational class was classified into nine groups using the original classification based on the 2008 version of the International Standardized Classification of Occupations (ISCO-08) major groups (International Labour Office 2012): manager, professional, technician, clerk, service and sales worker, craft and related trade worker, machine operator and assembler, laborer, and other. Work shift was classified into four groups using the original classification based on the previous study (Ohlander et al. 2015): day shift, shift work with night duty, shift work without night duty, and night shift.

\section{Statistical analysis}

Taking psychological distress (i.e., a total score for the K6 scale) as a dependent variable, hierarchical multiple regression analyses were conducted by gender and employment status in the following manner: potential confounders were initially entered into the model (Step 1) followed by the main effects of JI and RA (Step 2) and interaction term of JI $\times$ RA (Step 3). When the interaction effect of JI $\times$ RA in Step 3 emerged as significant, post hoc simple slope analyses were conducted at one standard deviation (SD) above/below the mean score of RA. In a series of analyses, $R$-squared $\left(R^{2}\right)$, adjusted $R^{2}$, and $\Delta R^{2}$ (i.e., increase in $R^{2}$ compared from the previous one) were calculated in each step to assess the model fit. In addition, residual analyses were conducted to estimate the amount of autocorrelation in the residuals using the Durbin-Watson statistic (ranging from 0 to 4.0 and a value of 2.0 means that there is no autocorrelation) and to check whether the standardized residuals are normally distributed. Prior to the analyses, total scores of JI and RA were mean-centered. It should be noted that the number of non-permanent male employees was quite small $(n=29)$, which might lead to reduced chance of detecting a true association due to low statistical power. Therefore, for non-permanent male employees, hierarchical multiple regression analyses were not conducted; instead, only information on demographic and occupational characteristics and scale scores was provided (see Table 1 described later). The level of significance was 0.05 (two-tailed). Statistical analyses were performed using IBM SPSS Statistics version 19 for Windows.

\section{Results}

During the survey period, 3461 employees completed the self-administered questionnaire (response rate $=95.3 \%$ ). After excluding 472 employees who had at least one missing response on the questionnaires, the final sample comprised
2989 respondents (2184 men and 805 women: valid response rate $=82.3 \%$ ). In the present sample, among non-permanent employees, men perceived significantly higher levels of JI compared to women, after adjusting for demographic and occupational characteristics ( $p$ for Bonferroni multiple comparison test $<0.001$ ). Furthermore, among men, nonpermanent employees perceived significantly higher levels of JI compared to permanent employees ( $p$ for Bonferroni multiple comparison test $=0.003$ ). On the other hand, difference in RA or psychological distress between genders or employment status was not significant. Detailed demographic and occupational characteristics and scale scores by gender and employment status are shown in Table 1.

Table 2 shows the results for permanent male employees. After adjusting for demographic and occupational characteristics (Step 2), both JI and RA had significant positive main effects on psychological distress $(\beta=0.268, p<0.001$ and $\beta=0.233, p<0.001$, respectively). When we added the interaction term of JI $\times$ RA in the model (Step 3), the main effects of JI and RA remained significant ( $\beta=0.256$, $p<0.001$ and $\beta=0.229, p<0.001$, respectively). The interaction effect of JI $\times$ RA was also significant $(\beta=0.053$, $p=0.010$ ). Furthermore, the interaction term of $\mathrm{JI} \times \mathrm{RA}$ significantly contributed to the explanation of psychological distress $\left(\Delta R^{2}=0.030, p=0.010\right)$. Post hoc simple slope analyses showed that the simple slope of JI was greater at higher levels of RA (i.e., one SD above the mean) $(\beta=0.300$, $p<0.001$ ) rather than lower levels of RA (i.e., one SD below the mean) $(\beta=0.212, p<0.001)$ (Fig. 1).

Table 3 shows the results for permanent female employees. After adjusting for demographic and occupational characteristics (Step 2), both JI and RA had significant positive main effects on psychological distress $(\beta=0.173, p=0.002$ and $\beta=0.143, p=0.009$, respectively). When we added the interaction term of JI $\times$ RA in the model (Step 3), the main effects of JI and RA remained significant $(\beta=0.182$, $p=0.001$ and $\beta=0.145, p=0.009$, respectively). However, in contrast to permanent male employees, the interaction effect of JI $\times$ RA was not significant $(\beta=-0.036, p=0.500)$, and the interaction term of JI $\times$ RA did not significantly contribute to the explanation of psychological distress $\left(\Delta R^{2}=0.001, p=0.500\right)$.

Table 4 shows the results for non-permanent female employees. After adjusting for demographic and occupational characteristics (Step 2), both JI and RA had significant positive main effects on psychological distress $(\beta=0.336$, $p<0.001$ and $\beta=0.130, p=0.004$, respectively). When we added the interaction term of JI $\times$ RA in the model (Step 3 ), the main effects of JI and RA remained significant $(\beta=0.335, p<0.001$ and $\beta=0.129, p=0.003$, respectively). However, as with the case of permanent female employees, the interaction effect of JI $\times$ RA was not significant $(\beta=0.003, p=0.952)$, and the interaction term of $\mathrm{JI} \times \mathrm{RA}$ 


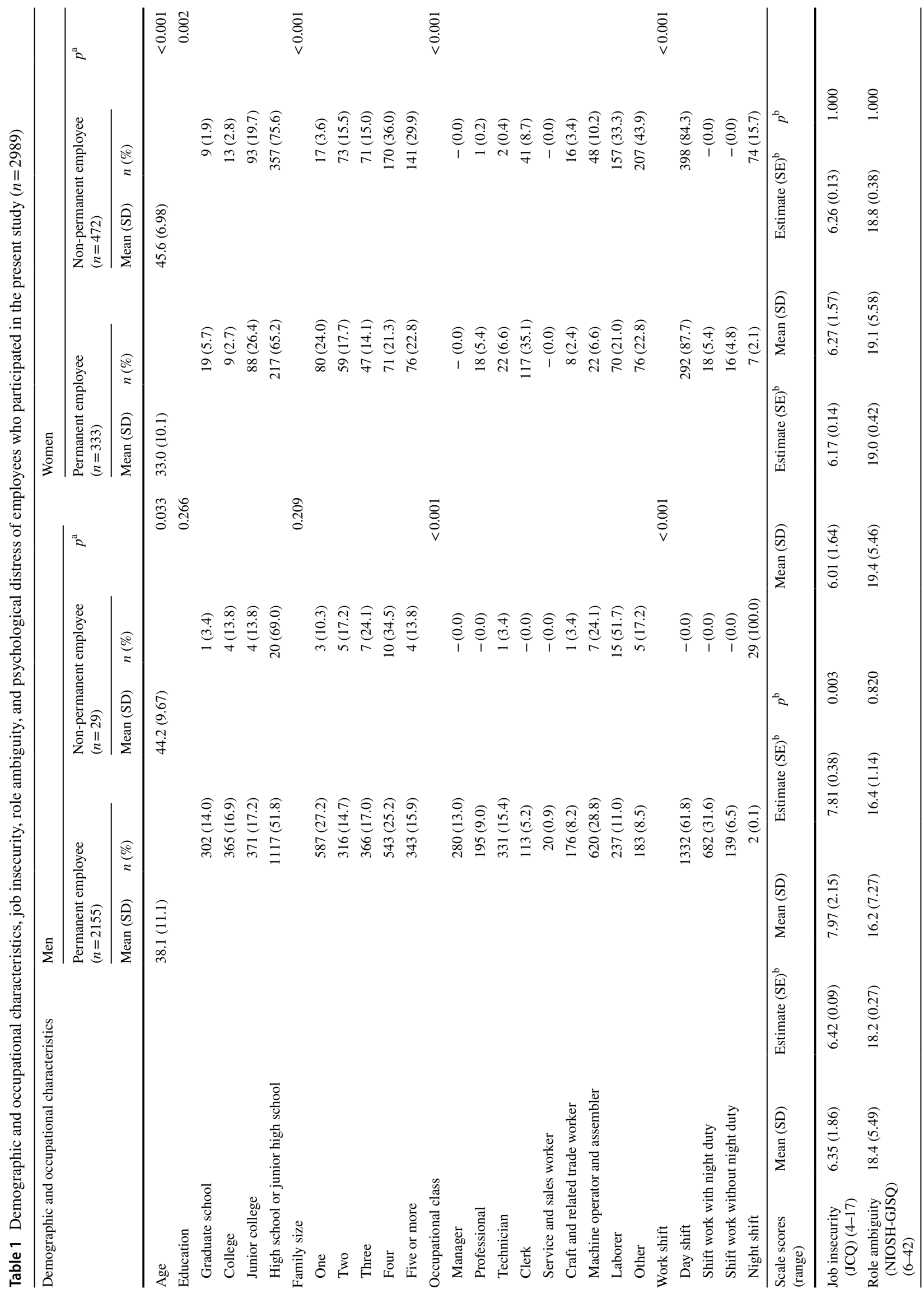


did not significantly contribute to the explanation of psychological distress $\left(\Delta R^{2}=0.000, p=0.952\right)$.

For residual analyses of each group, the Durbin-Watson statistic ranged from 1.979 to 2.048 (i.e., very near to the optimum of 2.0) and the residual was normally distributed.

\section{Discussion}

The present study demonstrated the significant main effects of JI and RA on psychological distress regardless of gender or employment status. The significant interaction effect of $\mathrm{JI} \times \mathrm{RA}$ was observed among permanent male employees in that the association of JI with psychological distress was greater when they perceived higher levels of RA. On the other hand, the interaction effect of JI $\times$ RA was not significant among permanent or non-permanent female employees. Non-permanent male employees were not included in the statistical analyses due to a small sample size.

In the present study, the significant main effect of JI on psychological distress was observed after adjusting for potential confounders (i.e., demographic and occupational characteristics) (Steps 2 and 3) regardless of gender or employment status. This finding is consistent with previous meta-analytic studies and a systematic review showing the association of JI with poor mental health, such as common mental disorders and depressive symptoms (Cheng and Chan 2008; Kim and von dem Knesebeck 2016; Stansfeld and Candy 2006; Sverke et al. 2002; Theorell et al. 2015). Similarly, the significant main effect of RA on psychological distress was observed after adjusting for potential confounders (Steps 2 and 3), regardless of gender or employment status. This finding is also consistent with a previous meta-analytic study and a systematic review showing the association of RA with depression and common mental health problems (Harvey et al. 2017; Schmidt et al. 2014). The present study replicated the findings from previous meta-analytic studies and systematic reviews on JI and RA in terms of psychological distress.

Furthermore, the interaction effect of JI $\times$ RA on psychological distress was significant after adjusting for potential confounders (Step 3) among permanent male employees. Post hoc simple slope analyses showed that the association of JI with psychological distress was greater when they perceived higher levels of RA. These findings support our hypothesis. Based on the COR theory introduced earlier (Hobfoll 1989), high RA (or low RC) may inhibit comprehension of employees' work responsibilities, which may lead to a lack of clear expectations and increased uncertainty at the workplace. In such situation, the association of JI with psychological distress may be strengthened, because employees may be less likely to feel the control over an insecure situation (Tomas and Seršić 2015). On the other 
Table 2 Associations of demographic and occupational characteristics, job insecurity, and role ambiguity with psychological distress among permanent male employees: hierarchical multiple regression analysis (2155 men)

\begin{tabular}{|c|c|c|c|c|c|c|c|}
\hline \multirow{2}{*}{\multicolumn{2}{|c|}{ Standardized coefficient $(\beta)$}} & \multicolumn{2}{|l|}{ Step 1} & \multicolumn{2}{|l|}{ Step 2} & \multicolumn{2}{|l|}{ Step 3} \\
\hline & & Estimate & $p$ & Estimate & $p$ & Estimate & $p$ \\
\hline \multicolumn{2}{|l|}{ Age } & -0.096 & $<0.001$ & -0.112 & $<0.001$ & -0.113 & $<0.001$ \\
\hline \multicolumn{8}{|c|}{ Education (vs. high school or junior high school) } \\
\hline \multicolumn{2}{|c|}{ Graduate school } & -0.014 & 0.603 & -0.012 & 0.622 & -0.011 & 0.643 \\
\hline \multicolumn{2}{|l|}{ College } & -0.035 & 0.178 & -0.023 & 0.333 & -0.023 & 0.332 \\
\hline \multicolumn{2}{|l|}{ Junior college } & -0.040 & 0.088 & -0.035 & 0.099 & -0.034 & 0.106 \\
\hline \multicolumn{8}{|c|}{ Family size (vs. one) } \\
\hline \multicolumn{2}{|c|}{ Two } & -0.058 & 0.022 & -0.048 & 0.042 & -0.049 & 0.038 \\
\hline \multicolumn{2}{|l|}{ Three } & -0.033 & 0.211 & -0.018 & 0.444 & -0.017 & 0.468 \\
\hline \multicolumn{2}{|l|}{ Four } & -0.052 & 0.064 & -0.037 & 0.159 & -0.037 & 0.152 \\
\hline \multicolumn{2}{|l|}{ Five or more } & -0.052 & 0.054 & -0.038 & 0.126 & -0.039 & 0.119 \\
\hline \multicolumn{8}{|c|}{ Occupational class (vs. other) } \\
\hline \multicolumn{2}{|l|}{ Manager } & -0.048 & 0.148 & 0.029 & 0.338 & 0.028 & 0.355 \\
\hline \multicolumn{2}{|l|}{ Professional } & -0.030 & 0.353 & -0.009 & 0.747 & -0.008 & 0.783 \\
\hline \multicolumn{2}{|l|}{ Technician } & 0.007 & 0.843 & 0.008 & 0.798 & 0.011 & 0.739 \\
\hline \multicolumn{2}{|l|}{ Clerk } & 0.009 & 0.742 & 0.035 & 0.157 & 0.036 & 0.149 \\
\hline \multicolumn{2}{|c|}{ Service and sales worker } & -0.017 & 0.466 & -0.007 & 0.736 & -0.007 & 0.724 \\
\hline \multicolumn{2}{|c|}{ Craft and related trade worker } & -0.005 & 0.866 & 0.002 & 0.951 & 0.005 & 0.861 \\
\hline \multicolumn{2}{|c|}{ Machine operator and assembler } & 0.033 & 0.410 & 0.019 & 0.606 & 0.022 & 0.544 \\
\hline \multicolumn{2}{|c|}{ Laborer } & 0.011 & 0.718 & 0.017 & 0.546 & 0.019 & 0.516 \\
\hline \multicolumn{8}{|c|}{ Work shift (vs. day shift) } \\
\hline \multicolumn{2}{|c|}{ Shift work with night duty } & -0.083 & 0.004 & -0.095 & $<0.001$ & -0.096 & $<0.001$ \\
\hline \multicolumn{2}{|c|}{ Shift work without night duty } & 0.031 & 0.172 & 0.000 & 0.995 & -0.001 & 0.964 \\
\hline \multicolumn{2}{|c|}{ Night shift } & -0.009 & 0.663 & -0.019 & 0.349 & -0.015 & 0.463 \\
\hline \multicolumn{2}{|l|}{ Job insecurity } & & & 0.268 & $<0.001$ & 0.256 & $<0.001$ \\
\hline \multicolumn{2}{|l|}{ Role ambiguity } & & & 0.233 & $<0.001$ & 0.229 & $<0.001$ \\
\hline Job insecurity $\times$ rc & biguity & & & & & 0.053 & 0.010 \\
\hline Model fit indices & Estimate & $p$ & Estimate & $p$ & & Estimate & $p$ \\
\hline$R^{2}$ & 0.027 & - & 0.175 & & & 0.178 & - \\
\hline Adjusted $R^{2}$ & 0.019 & - & 0.167 & & & 0.169 & - \\
\hline$\Delta R^{2}$ & 0.027 & $<0.001$ & 0.148 & & & 0.030 & 0.010 \\
\hline
\end{tabular}

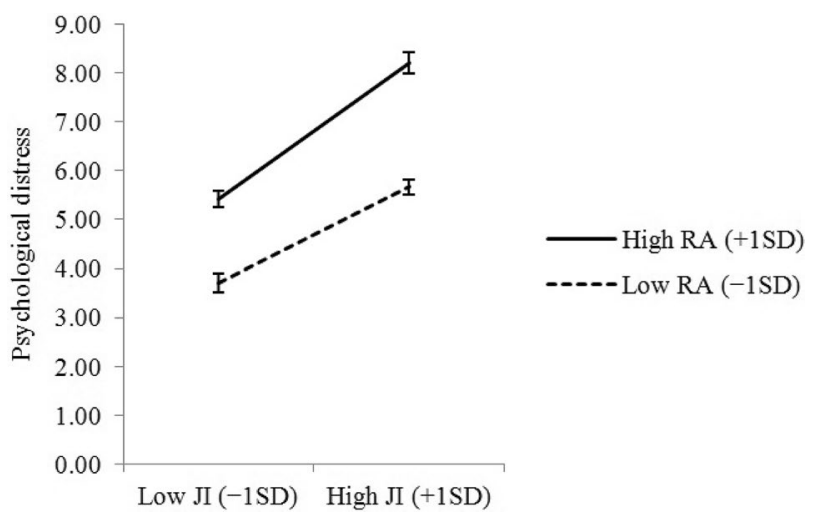

Fig. 1 Interaction between job insecurity (JI) and role ambiguity (RA) on psychological distress among permanent male employees: post hoc simple slope analysis (2155 men) hand, this finding can also indicate that the association of RA with psychological distress was greater when they perceived higher levels of JI. According to Hackman and Oldham's (1980) 'job characteristics model', the positive effect of psychosocial working conditions on work outcomes (e.g., job satisfaction and work motivation) occurs only when the employees' concerns with job security are satisfied. Therefore, conversely, in the situation where such concerns are dissatisfied, the association of adverse working conditions, like high RA, with psychological distress may be strengthened. Such a modifying effect of JI on the association of RA with mental health outcomes should be examined more closely in the future.

In contrast to permanent male employees, the interaction effect of $\mathrm{JI} \times \mathrm{RA}$ on psychological distress was not 
Table 3 Associations of demographic and occupational characteristics, job insecurity, and role ambiguity with psychological distress among permanent female employees: hierarchical multiple regression analysis (333 women)

\begin{tabular}{|c|c|c|c|c|c|c|c|}
\hline \multirow{2}{*}{\multicolumn{2}{|c|}{ Standardized coefficient $(\beta)$}} & \multicolumn{2}{|l|}{ Step 1} & \multicolumn{2}{|l|}{ Step 2} & \multicolumn{2}{|l|}{ Step 3} \\
\hline & & Estimate & $p$ & Estimate & $p$ & Estimate & $p$ \\
\hline \multicolumn{2}{|l|}{ Age } & -0.278 & $<0.001$ & -0.273 & $<0.001$ & -0.269 & $<0.001$ \\
\hline \multicolumn{8}{|c|}{ Education (vs. high school or junior high school) } \\
\hline \multicolumn{2}{|c|}{ Graduate school } & 0.101 & 0.084 & 0.101 & 0.074 & 0.104 & 0.068 \\
\hline \multicolumn{2}{|l|}{ College } & 0.039 & 0.477 & 0.013 & 0.806 & 0.014 & 0.792 \\
\hline \multicolumn{2}{|l|}{ Junior college } & 0.057 & 0.335 & 0.050 & 0.383 & 0.054 & 0.348 \\
\hline \multicolumn{8}{|c|}{ Family size (vs. one) } \\
\hline \multicolumn{2}{|c|}{ Two } & -0.076 & 0.278 & -0.071 & 0.292 & -0.070 & 0.305 \\
\hline \multicolumn{2}{|l|}{ Three } & -0.082 & 0.230 & -0.089 & 0.181 & -0.090 & 0.175 \\
\hline \multicolumn{2}{|l|}{ Four } & -0.151 & 0.035 & -0.138 & 0.046 & -0.139 & 0.045 \\
\hline \multicolumn{2}{|c|}{ Five or more } & -0.035 & 0.633 & -0.029 & 0.682 & -0.030 & 0.665 \\
\hline \multicolumn{8}{|c|}{ Occupational class (vs. other) ${ }^{\mathrm{a}}$} \\
\hline \multicolumn{2}{|l|}{ Professional } & -0.066 & 0.310 & -0.062 & 0.317 & -0.060 & 0.337 \\
\hline \multicolumn{2}{|l|}{ Technician } & -0.064 & 0.354 & -0.067 & 0.314 & -0.069 & 0.304 \\
\hline \multicolumn{2}{|l|}{ Clerk } & -0.050 & 0.506 & -0.043 & 0.558 & -0.039 & 0.599 \\
\hline \multicolumn{2}{|c|}{ Craft and related trade worker } & 0.020 & 0.720 & 0.027 & 0.616 & 0.025 & 0.641 \\
\hline \multicolumn{2}{|c|}{ Machine operator and assembler } & -0.080 & 0.202 & -0.063 & 0.300 & -0.060 & 0.325 \\
\hline \multicolumn{2}{|c|}{ Laborer } & -0.079 & 0.235 & -0.087 & 0.178 & -0.085 & 0.191 \\
\hline \multicolumn{8}{|c|}{ Work shift (vs. day shift) } \\
\hline \multicolumn{2}{|c|}{ Shift work with night duty } & 0.094 & 0.117 & 0.083 & 0.155 & 0.083 & 0.154 \\
\hline \multicolumn{2}{|c|}{ Shift work without night duty } & 0.047 & 0.391 & 0.033 & 0.531 & 0.031 & 0.553 \\
\hline \multicolumn{2}{|l|}{ Night shift } & -0.012 & 0.818 & -0.023 & 0.660 & -0.027 & 0.611 \\
\hline \multicolumn{2}{|l|}{ Job insecurity } & & & 0.173 & 0.002 & 0.182 & 0.001 \\
\hline \multicolumn{2}{|l|}{ Role ambiguity } & & & 0.143 & 0.009 & 0.145 & 0.009 \\
\hline \multicolumn{4}{|c|}{ Job insecurity $\times$ role ambiguity } & & & -0.036 & 0.500 \\
\hline Model fit indices & Estimate & $p$ & Estimate & \multicolumn{2}{|c|}{$p$} & Estimate & $p$ \\
\hline$R^{2}$ & 0.142 & - & 0.204 & & & 0.205 & - \\
\hline Adjusted $R^{2}$ & 0.096 & - & 0.156 & & & 0.154 & - \\
\hline$\Delta R^{2}$ & 0.142 & $<0.001$ & 0.062 & & & 0.001 & 0.500 \\
\hline
\end{tabular}

${ }^{\text {a }}$ There were no managers or service and sales workers among permanent female employees

significant among permanent or non-permanent female employees. This finding suggests that the extent of RA does not affect the association of JI with psychological distress, which does not support our hypothesis. The framework of gender-role ideology might explain the gender difference in the interaction effect of $\mathrm{JI} \times \mathrm{RA}$, suggesting that work roles and breadwinning are more central to the identity of men, whereas family roles are more central to the identity of women (Barnett et al. 1995; Simon 1992). Since in the Japanese society, such a traditional gender-role ideology persists (Katsurada and Sugihara 2002), women may be less likely to be aware of the extent of ambiguity (or clarity) of their work roles in the context of JI compared to men. However, as the present sample of permanent and non-permanent female employees was small and drawn from one company, the finding remains uncertain and further research is needed to explore gender difference in the interaction effect of JI $\times$ RA using a broader sample.

In the present study, among non-permanent employees, men perceived significantly higher levels of JI compared to women. Similar tendency, although non-significant, was observed among permanent employees. The above-mentioned framework of gender-role ideology might also explain this finding. As introduced earlier, Charles and James (2005) argued that the gender-role ideology, suggesting that men are expected to be the primary breadwinners, is specifically linked to gender differences in experiences and perceptions of JI, with men feeling more insecure compared to women. Therefore, the present finding may reflect such a gender-role ideology that persists in the Japanese society (Katsurada and Sugihara 2002). 
Table 4 Associations of demographic and occupational characteristics, job insecurity, and role ambiguity with psychological distress among non-permanent female employees: hierarchical multiple regression analysis (472 women)

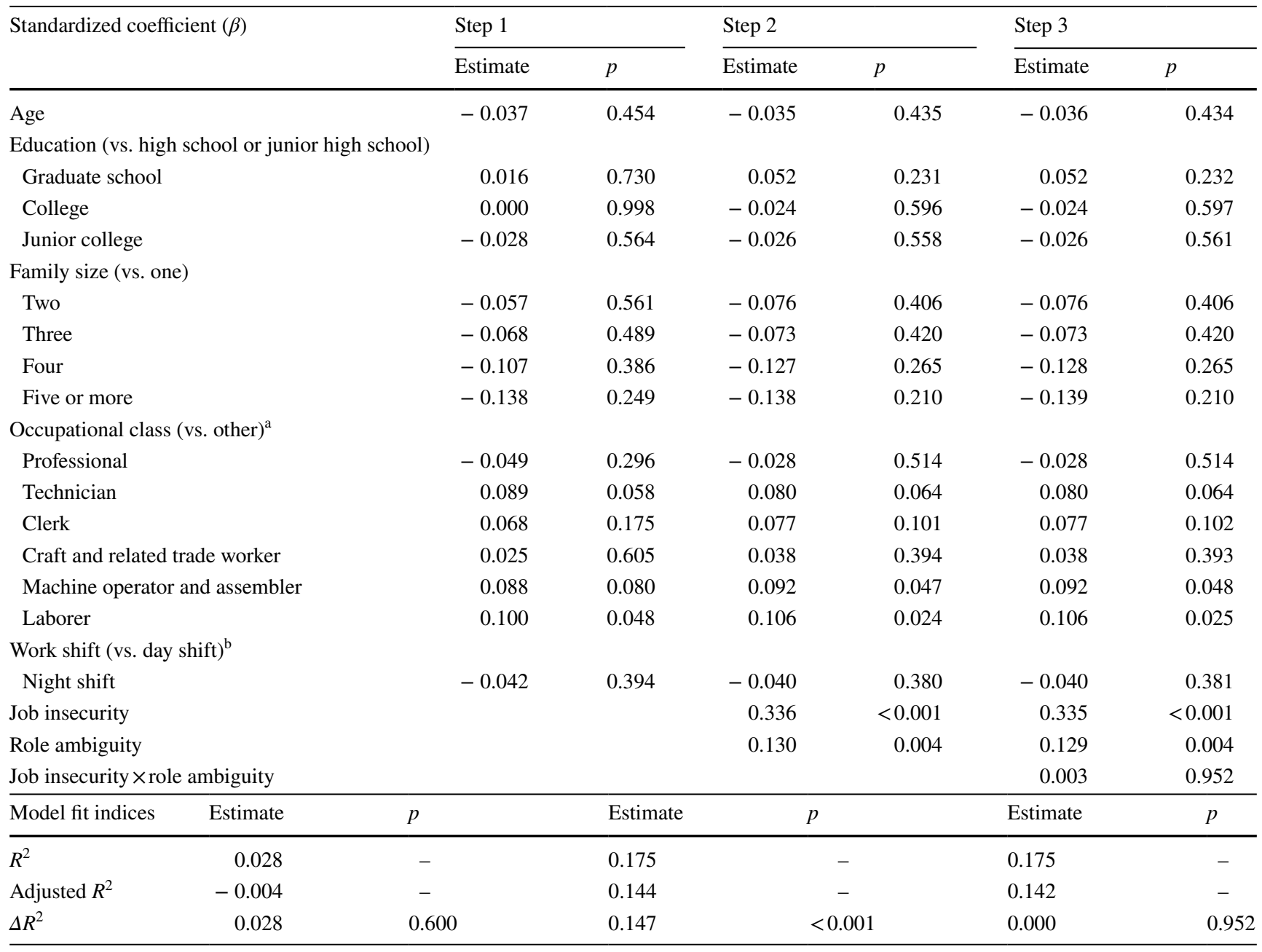

${ }^{\mathrm{a}}$ There were no managers or service and sales workers among non-permanent female employees

${ }^{b}$ All non-permanent female employees were day shift workers or night shift workers

Furthermore, among women, the main effect of JI on psychological distress for non-permanent employees was about 1.8 times greater compared to permanent employees ( $\beta=0.335$ vs. 0.182 in Step 3). This finding is consistent with earlier findings of Koslowsky (1998), implying that the negative effects of two stressors (in the present case, JI and non-permanent employment) on mental health outcomes may strengthen each other in a multiplicative way. However, recent research has suggested that the association of JI with mental health outcomes is greater among permanent employees rather than non-permanent employees (e.g., De Witte and Näswall 2003). Bernhard-Oettel et al. (2005) have suggested that one of the reasons for such a mixed pattern of findings is that research on the interaction effect of JI with employment status typically does not consider the heterogeneous nature of non-permanent employees, such as contract duration, employment prospects, and preference for non-permanent employment. Therefore, to examine the interaction effect of JI with employment status on psychological distress more precisely, future studies should consider such heterogeneity of non-permanent employment.

The present study had some limitations. First, although the response rate in the present study was high, those who perceived higher levels of JI, RA, and psychological distress may have been less likely to participate in the present study. Second, although we adjusted for family size as a potential confounder, information on marital status was not obtained, since it is sensitive personal information. László et al. (2010) have suggested that JI has more deleterious effects on single persons than on married or cohabiting ones, as the social and the financial support from a spouse is likely to have an important protective effect. The present study could not completely eliminate such confounding bias. Third, as described earlier, the reliability 
of the JCQ JI scale was low in the present sample, which may have produced either overestimates or underestimates of substantive associations, although a previous cross-cultural study reported a similar level of reliability (Karasek et al. 1998). Fourth, the present sample was recruited from one manufacturing company with stable business conditions in Japan; therefore, the generalization of the present findings should be done with caution. Furthermore, as described earlier, non-permanent male employees could not be included in the statistical analyses due to a small sample size; therefore, a future study could try to replicate our findings with non-permanent male employees. Fifth, although a recent study on JI utilized a multilevel approach while considering its contextual effect (Låstad et al. 2016), the present study could not examine such an effect due to lack of information concerning the department of each participant. Sixth, causal inferences could not be made due to the cross-sectional nature of the study. The present findings seem to indicate that those who experienced higher levels of psychological distress may have been more likely to assess JI and/or RA as high. Finally, our main outcome was self-reported psychological distress; therefore, further studies could focus on more severe mental health outcomes, such as doctor-diagnosed depression.

Despite several limitations described above, the present study suggests that JI and RA have an interaction effect on psychological distress, at least among Japanese permanent male employees. JI is the most stressful aspect of the process leading to unemployment, having a worse effect on employees than unemployment does itself (Nella et al. 2015); therefore, to maintain and promote good mental health among employees, stronger employment measures and unemployment protection system should be developed at a national policy level (Uutela 2010). On the other hand, in the workplace, providing a clear description of job role may be effective in the reducing psychological distress associated with $\mathrm{JI}$, especially among permanent male employees.

Acknowledgements The present study was supported by MEXT KAKENHI Grant Number 21119001 (Grant-in-Aid for Scientific Research on Innovative Areas) and JSPS KAKENHI Grant Numbers 26253042 (Grant-in-Aid for Scientific Research (A)) and 17K09172 (Grant-inAid for Scientific Research (C)).

\section{Compliance with ethical standards}

Conflict of interest The authors declare that they have no conflict of interest.

Ethical approval All procedures performed in studies involving human participants were in accordance with the ethical standards of the institutional and/or national research committee and with the 1964 Helsinki declaration and its later amendments or comparable ethical standards.
Informed consent Informed consent was obtained from all individual participants included in the study.

Open Access This article is distributed under the terms of the Creative Commons Attribution 4.0 International License (http://creativecommons.org/licenses/by/4.0/), which permits unrestricted use, distribution, and reproduction in any medium, provided you give appropriate credit to the original author(s) and the source, provide a link to the Creative Commons license, and indicate if changes were made.

\section{Appendix: Job Content Questionnaire (JCQ) general job insecurity $(\mathrm{Jl})$ scale}

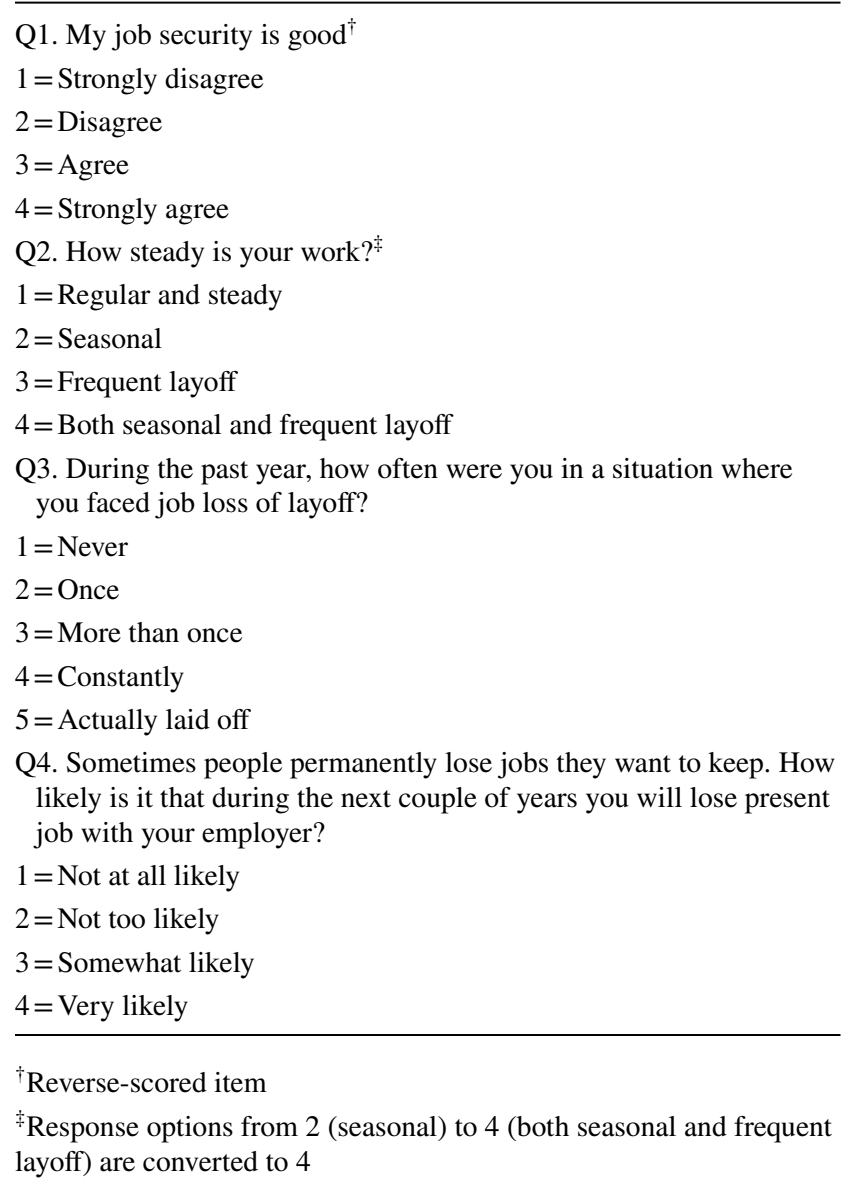

\section{References}

Abramis DJ (1994) Work role ambiguity, job satisfaction, and job performance: meta-analyses and review. Psychol Rep 75:1411-1433. https://doi.org/10.2466/pr0.1994.75.3f.1411

Adams GA, King LA, King DW (1996) Relationships of job and family involvement, family social support, and work-family conflict with 
job and life satisfaction. J Appl Psychol 81:411-420. https://doi. org/10.1037//0021-9010.81.4.411

Barnett RC, Raudenbush SW, Brennan RT, Pleck JH, Marshall NL (1995) Change in job and marital experiences and change in psychological distress: longitudinal study of dualearner couples. J Pers Soc Psychol 69:839-850. https://doi. org/10.1037/0022-3514.69.5.839

Bernhard-Oettel C, Sverke M, De Witte H (2005) Comparing three alternative types of employment with permanent full-time work: how do employment contract and perceived job conditions relate to health complaints? Work Stress 19:301-318. https://doi. org/10.1080/02678370500408723

Bøggild H, Burr H, Tüchsen F, Jeppesen HJ (2001) Work environment of Danish shift and day workers. Scand J Work Environ Health 27:97-105. https://doi.org/10.5271/sjweh.595

Charles N, James E (2005) Gender, job insecurity and the work-life balance. In: Houston D (ed) Work-life balance in the 21st century. Palgrave Macmillan, London, pp 170-188. https://doi. org/10.1057/9780230373594_9

Cheng GHL, Chan DKS (2008) Who suffers more from job insecurity? a meta-analytic review. Appl Psychol Int Rev 57:272-303. https:// doi.org/10.1111/j.1464-0597.2007.00312.x

de Lange A, Taris T, Jansen P, Smulders P, Houtman I, Kompier M (2006) Age as a factor in the relation between work and mental health: results of the longitudinal TAS survey. In: McIntyre S, Houdmont J (eds) Occupational health psychology: European perspectives on research, education and practice, vol 1. ISMAI Publications, Maia, pp 21-45

De Witte H (2005) Job insecurity: review of the international literature on definitions, prevalence, antecedents and consequences. SA J Ind Psychol 31:1-6. https://doi.org/10.4102/sajip.v31i4.200

De Witte H, Näswall K (2003) 'Objective' vs 'subjective' job insecurity: consequences of temporary work for job satisfaction and organizational commitment in four European countries. Econ Ind Democracy 24:149-188. https://doi.org/10.1177/01438 31X03024002002

De Witte H, De Cuyper N, Handaja Y, Sverke M, Näswall K, Hellgren J (2010) Associations between quantitative and qualitative job insecurity and well-being: a test in Belgian banks. Int Stud Manag Organ 40:40-56. https://doi.org/10.2753/ IMO0020-8825400103

Eatough EM, Chang CH, Miloslavic SA, Johnson RE (2011) Relationships of role stressors with organizational citizenship behavior: a meta-analysis. J Appl Psychol 96:619-632. https://doi. org/10.1037/a0021887

Fisher CD, Gitelson R (1983) A meta-analysis of the correlates of role conflict and role ambiguity. J Appl Psychol 68:320-333. https:// doi.org/10.1037/0021-9010.68.2.320

Fried Y, Slowik LH, Shperling Z, Franz C, Ben-David HA, Avital $\mathrm{N}$, Yeverechyahu U (2003) The moderating effect of job security on the relation between role clarity and job performance: a longitudinal field study. Hum Relat 56:787-805. https://doi. org/10.1177/00187267030567002

Furukawa TA, Kawakami N, Saitoh M, Ono Y, Nakane Y, Nakamura Y, Tachimori H, Iwata N, Uda H, Nakane H, Watanabe M, Naganuma Y, Hata Y, Kobayashi M, Miyake Y, Takeshima T, Kikkawa $\mathrm{T}$ (2008) The performance of the Japanese version of the K6 and K10 in the World Mental Health Survey Japan. Int J Methods Psychiatr Res 17:152-158. https://doi.org/10.1002/mpr.257

Greenhalgh L, Rosenblatt Z (1984) Job insecurity: toward conceptual clarity. Acad Manage Rev 9:438-448. https://doi.org/10.5465/ AMR.1984.4279673

Hackman JR, Oldham G (1980) Work redesign. Addison Wesley, Reading

Haratani T (1997) Psychometric properties of the JCQ and the NIOSH Generic Job Stress Questionnaire. In: Kato M (ed) Ministry of
Labour sponsored grant for the prevention of work-related illness: the 1996 report. Ministry of Labour, Tokyo, pp 15-20 (in Japanese)

Haratani T, Kawakami N, Araki S, Hurrell JJ Jr, Sauter SL, Swanson NG (1996) Psychometric properties and stability of the Japanese version of the NIOSH job stress questionnaire. In: 25th International Congress on Occupational Health (ed) 25th International Congress on Occupational Health, Book of Abstracts, Pt 2. p 25th International Congress on Occupational Health, Stockholm, pp 393

Harvey SB, Modini M, Joyce S, Milligan-Saville JS, Tan L, Mykletun A, Bryant RA, Christensen H, Mitchell PB (2017) Can work make you mentally ill? A systematic meta-review of work-related risk factors for common mental health problems. Occup Environ Med 74:301-310. https://doi.org/10.1136/oemed-2016-104015

Hellgren J, Sverke M, Isaksson K (1999) A two-dimensional approach to job insecurity: consequences for employee attitudes and well-being. Eur J Work Organ Psychol 8:179-195. https://doi. org/10.1080/135943299398311

Hobfoll SE (1989) Conservation of resources: a new approach at conceptualizing stress. Am Psychol 44:513-524. https://doi. org/10.1037/0003-066X.44.3.513

Hurrell JJ Jr, McLaney MA (1988) Exposure to job stress-a new psychometric instrument. Scand J Work Environ Health 14(Suppl 1):27-28

Inoue A, Kawakami N, Tsutsumi A, Shimazu A, Miyaki K, Takahashi M, Kurioka S, Eguchi H, Tsuchiya M, Enta K, Kosugi Y, Sakata $\mathrm{T}$, Totsuzaki T (2014) Association of job demands with work engagement of Japanese employees: comparison of challenges with hindrances (J-HOPE). PLOS ONE 9:e91583. https://doi. org/10.1371/journal.pone.0091583

International Labour Office (2012) International Standard Classification of Occupations ISCO-08. International Labour Office, Geneva

Jackson SE, Schuler RS (1985) A meta-analysis and conceptual critique of research on role ambiguity and role conflict in work settings. Organ Behav Hum Decis Process 36:16-78. https://doi. org/10.1016/0749-5978(85)90020-2

Jahoda M (1982) Employment and unemployment: a social-psychological analysis. Cambridge University Press, Cambridge

Karasek R (1985) Job Content Questionnaire and user's guide. University of Massachusetts at Lowell, Lowell

Karasek R, Brisson C, Kawakami N, Houtman I, Bongers P, Amick B (1998) The Job Content Questionnaire (JCQ): an instrument for internationally comparative assessments of psychosocial job characteristics. J Occup Health Psychol 3:322-355. https://doi. org/10.1037/1076-8998.3.4.322

Katsurada E, Sugihara Y (2002) Gender-role identity, attitudes toward marriage, and gender-segregated school backgrounds. Sex Roles 47:249-258. https://doi.org/10.1023/A:1021334710431

Kawakami N, Haratani T, Kobayashi F, Ishizaki M, Hayashi T, Fujita O, Aizawa Y, Miyazaki S, Hiro H, Masumoto T, Hashimoto S, Araki S (2004) Occupational class and exposure to job stressors among employed men and women in Japan. J Epidemiol 14:204211. https://doi.org/10.2188/jea.14.204

Kessler RC, Andrews G, Colpe LJ, Hiripi E, Mroczek DK, Normand SL, Walters EE, Zaslavsky AM (2002) Short screening scales to monitor population prevalences and trends in non-specific psychological distress. Psychol Med 32:959-976. https://doi. org/10.1017/S0033291702006074

Kim TJ, von dem Knesebeck O (2016) Perceived job insecurity, unemployment and depressive symptoms: a systematic review and meta-analysis of prospective observational studies. Int Arch Occup Environ Health 89:561-573. https://doi.org/10.1007/ s00420-015-1107-1 
Kimura T, Iso H, Honjo K, Ikehara S, Sawada N, Iwasaki M, Tsugane S (2016) Educational levels and risk of suicide in Japan: the Japan Public Health Center study (JPHC) Cohort I. J Epidemiol 26:315-321. https://doi.org/10.2188/jea.JE20140253

Koslowsky M (1998) Modeling the stress-strain relationship in work settings. Routledge, London

Kuroki M (2012) The deregulation of temporary employment and workers' perceptions of job insecurity. ILR Rev 65:560-577. https://doi.org/10.1177/001979391206500304

Låstad L, Näswall K, Berntson E, Seddigh A, Sverke M (2016) The roles of shared perceptions of individual job insecurity and job insecurity climate for work- and health-related outcomes: a multilevel approach. Econ Ind Democr (first published on March 11. 2016). https://doi.org/10.1177/0143831X16637129

László KD, Pikhart H, Kopp MS, Bobak M, Pajak A, Malyutina S, Salavecz G, Marmot M (2010) Job insecurity and health: a study of 16 European countries. Soc Sci Med 70:867-874. https://doi. org/10.1016/j.socscimed.2009.11.022

Lorant V, Deliège D, Eaton W, Robert A, Philippot P, Ansseau M (2003) Socioeconomic inequalities in depression: a meta-analysis. Am J Epidemiol 157:98-112. https://doi.org/10.1093/aje/kwf182

Lunau T, Siegrist J, Dragano N, Wahrendorf M (2015) The association between education and work stress: does the policy context matter? PLOS ONE 10:e0121573. https://doi.org/10.1371/journal. pone. 0121573

Marmot MG, Smith GD, Stansfeld S, Patel C, North F, Head J, White I, Brunner E, Feeney A (1991) Health inequalities among British civil servants: the Whitehall II study. Lancet 337:1387-1393. https://doi.org/10.1016/0140-6736(91)93068-K

Nella D, Panagopoulou E, Galanis N, Montgomery A, Benos A (2015) Consequences of job insecurity on the psychological and physical health of Greek civil servants. Biomed Res Int 2015:673623. https://doi.org/10.1155/2015/673623

Ohlander J, Keskin MC, Stork J, Radon K (2015) Shift work and hypertension: prevalence and analysis of disease pathways in a German car manufacturing company. Am J Ind Med 58:549-560. https:// doi.org/10.1002/ajim.22437

Panaccio A, Vandenberghe C (2011) The relationships of role clarity and organization-based self-esteem to commitment to supervisors and organizations and turnover intentions. J Appl Soc Psychol 41:1455-1485. https://doi.org/10.1111/j.1559-1816.2011.00764.x

Rizzo JR, House RJ, Lirtzman SI (1970) Role conflict and ambiguity in complex organizations. Adm Sci Q 15:150-163. https://doi. org/10.2307/2391486
Schmidt S, Roesler U, Kusserow T, Rau R (2014) Uncertainty in the workplace: examining role ambiguity and role conflict, and their link to depression-a meta-analysis. Eur J Work Organ Psychol 23:91-106. https://doi.org/10.1080/1359432X.2012.711523

Shen Y (2005) A meta-analysis of role ambiguity and role conflict on IS professional job satisfaction. In: HICSS 2005-38th Hawaii International Conference on System Sciences (ed) Proceedings of the 38th Annual Hawaii International Conference on System Sciences. IEEE, Big Island, pp 263b. https://doi.org/10.1109/ HICSS.2005.22

Simon RW (1992) Parental role strains, salience of parental identity and gender differences in psychological distress. J Health Soc Behav 33:25-35

Stansfeld S, Candy B (2006) Psychosocial work environment and mental health - a meta-analytic review. Scand J Work Environ Health 32:443-462. https://doi.org/10.5271/sjweh.1050

Sverke M, Hellgren J, Näswall K (2002) No security: a meta-analysis and review of job insecurity and its consequences. J Occup Health Psychol 7:242-264. https://doi.org/10.1037/1076-8998.7.3.242

Theorell T, Hammarström A, Aronsson G, Träskman-Bendz L, Grape T, Hogstedt C, Marteinsdottir I, Skoog I, Hall C (2015) A systematic review including meta-analysis of work environment and depressive symptoms. BMC Public Health 15:738. https://doi. org/10.1186/s12889-015-1954-4

Tomas J, Seršić DM (2015) Job insecurity and health among industrial shift workers: the role of organizational context. Psihologia Resurselor Umane 13:189-205. https://doi.org/10.24837/ pru.2015.2.238

Tsutsumi A (2016) Work stress and health: the case of Japan. In: Siegrist J, Wahrendorf M (eds) Work stress and health in a globalized economy. Springer, Düsseldorf, pp 173-188. https://doi. org/10.1007/978-3-319-32937-6_8

Uutela A (2010) Economic crisis and mental health. Curr Opin Psychiatry 23:127-130. https://doi.org/10.1097/YCO.0b013e328336657d

Virtanen P, Vahtera J, Kivimäki M, Pentti J, Ferrie J (2002) Employment security and health. J Epidemiol Community Health 56:569574. https://doi.org/10.1136/jech.56.8.569

Vogel M, Braungardt T, Meyer W, Schneider W (2012) The effects of shift work on physical and mental health. J Neural Transm 119:1121-1132. https://doi.org/10.1007/s00702-012-0800-4

Warr PB (1984) Economic recession and mental health: a review of research. Tijdschrift voor Sociale Gezondheidszorg 62:298-308 